\title{
3G MULTIMEDIA CONTENT PRODUCTION AS SOCIAL COMMUNICATION
}

\author{
Christine Satchel \\ Associate Professor Supriya Singh \\ RMIT University and Smart Internet Technology CRC \\ christine.satchell@rmit.edu.au supriya.singh@rmit.edu.au \\ Associate Professor John Zic \\ University of New South Wales and Smart Internet Technology CRC \\ johnz@cse.unsw.edu.au
}

\begin{abstract}
Young people are taking advantage of the ever-increasing accessibility and technical capabilities of 3G phones and the Internet to represent their experiences through multimedia content. However, this practice is inhibited by design shortcomings which don't adequately protect the privacy of content, problemitise content management and which limit distribution. This paper explores how possible design solutions were envisioned thorough the use of a scenario, called the Trophy Room.
\end{abstract}

\section{Keywords}

Multimedia content production, privacy, archiving, distribution, $3 \mathrm{G}$ phones.

\section{INTRODUCTION}

A central theme in recent studies by Taylor and Harper (2002) and Howard et al (2002) is that the importance young users place on expressing their social identity in the real world extends into the digital world. This was supported in the two studies at the centre of this paper which were carried out as part of the Smart Internet Technology CRC research projects: the Young People study and the Secure Identity Management ${ }^{6}$ project. The studies found that young people are taking advantage of $3 \mathrm{G}$ telephone systems and the Internet to produce and merge bits of data to create their ideal digital self' through which they communicate socially. This means that instead of voice or text, users are communicating through a hybrid of still and moving images, sound-bytes, symbols and logos. This is in keeping with Counts and Fellheimer (2004) who found that "Lightweight photo sharing, particularly via mobile devices, is fast becoming a common communication medium used for maintaining a presence in the lives of friends and family".

\section{METHODOLOGY}

The two studies looked at 35 technically savvy users aged 18-30, living in Melbourne, Australia. Central to the research is the attempt to understand how young people express their social identity using new digital technologies. The search for emerging themes, user needs and design implications is at the center of the research. During the initial interviews the 'open-ended interview method' (Minichello: 1995) was used. The data was analyzed using NUD*IST 4, a computer program for the analysis of qualitative data. The following themes and user needs emerged from the analysis. Each user needs maps onto a theme.

${ }^{6}$ The authors would like to thank Telstra for supporting this project 


\section{EMERGING THEMES \& USER NEEDS}

Overall Theme - The Importance of Digital Identity: Users in the studies indicated that interpreting or reading other peoples' virtual identities provided a means of identifying what the other person was like. As one user stated, "Their synthesized persona is quite revealing." Furthermore, users indicated that they derive pleasure from creating a digital identity that reveals the persona they wish to convey.

General User Need - Identity as Disclosure: This is significant from a user needs perspective because it indicates that creating a digital identity is not only about how much information can be restricted but rather what is revealed. This illustrates that identity should not just be thought of in terms of how anonymity can be enforced.

Emerging Theme 1 - 'Cut and Paste' Multi Media Content as Social Communication. In order to create more dynamic digital identities users reported that they are using a 'cut and paste' approach to communicate through content. "I take digital photos and videos with my phone. Then I email them to my computer, download songs, attach it all to an email and send it to my friends." While another user stated "I can listen to my voice mail messages on the Internet. Then I can save them and use them as samples. Then I can email them back to friends and include pictures of them, or bits of their favourite song or something as birthday present." This is reminiscent of the behaviour of text messaging that Taylor and Harper (2002) reported, where a text message was not so much about what it said, but as an expression of friendship.

User Need 1 - Maintaining Control of the Privacy of Content: While users enjoyed using multimedia content as a form of social communication, 17 users in the studies explicitly stated that it is content that they have produced themselves that is the most important to protect in terms of privacy. One user in the studies said she is more concerned with protecting the privacy of the digital pictures on her phone than she is with protecting her Internet banking details. Other users indicated that a major concern with sharing content is making sure that only the intended people see it. These privacy concerns also explain why users said that while they wanted to communicate through home produced content, they were often reluctant to just send a picture or video out because once you do that you loose control over its distribution.

Emerging Theme 2 - Wrapping the Message in Content (Digital Tokens): Other examples of the ways in which users in the studies were using content as a form of social communication were embedding a picture in the bottom of every email instead of a signature. Furthermore, users in the studies indicate a desire for this paradigm to be turned around - so that the dominant part of the message is the picture itself embedded with the social message. "What I like about my new (3G) phone is that I can send a picture that I have taken and that's the message. I can add text too if I want." Essentially, the content becomes the 'wrapper' for the message. It can be seen how for the users in the studies, digital communication can now be more dynamic, so instead of traditional voice or text a message can be a combination of multimedia data embed in a single message or 'token'. However, with this increase in the use of multimedia content comes the difficulty in managing all the bits of data. 
User Need 2 - Improved Content Management: Users reported that they are mixing more and more bits of multimedia content together in a single message, reminiscent of the way a DJ mixes music samples together into a single track. However, there is a distinct problem arising in that users are finding it increasingly difficult to manage the bits of data that constitute their digital content collection. "The problem is I can't find things when I need them. Where did I put that photo, or keep that song, or the last thing that I mixed together." This indicates that users' need a more centralised place to keep their multimedia content from which they can gather together the desired elements into a single message or 'token'. Furthermore, digital content can be quite sentimental and users in the studies report that content stored on $3 \mathrm{G}$ phones is particularly vulnerable to loss. Three users reported that their phones crashed resulting in content being lost, while the handsets themselves are vulnerable to loss or theft. This indicates a need for a remote backup archive, and although users can currently back up content from $3 \mathrm{G}$ phones on their computer, this content it is not easily retrievable remotely via $3 \mathrm{G}$ phones.

Emerging Theme 3 - Content Production across Channels: The studies found that as $3 \mathrm{G}$ phones and Internet technologies converge, users are merging the two communication channels. For example, taking photos with their phone, downloading them to their computers, editing them on their desktop and then distributing them for free via group email. This is significant because as Counts and Fellheimer (2004) point out, both channels have advantages and disadvantages. The user studies proved to be helpful in indicating how users are taking advantage of the best of both channels to combine mobile and Internet technologies to create, circulate, distribute and archive content.

User Need 3 - Peer to Peer Sharing: Users in the studies reported that their ability to share experiences that they have produced themselves via text, images and sound bytes is limited by technical problems such as the incompatibility of handsets. For example, a homemade multimedia message produced on a NEC phone cannot be transmitted to a Nokia handset. Users in the studies report that these fears and limitations force them to resort to channels where they can download, for a fee, commercially produced content. This is significant because for the users in the studies, most of the fun of producing their own content was sharing it instantaneously with friends. If users have to wait until they get to their computer to share their content the moment may be lost. This does not mean that users don't still consume content rather they resort to downloading commercially produced content instead.

\section{TRANSLATING USER PROBLEMS INTO A SCENARIO}

Content, such as digital pictures, play a big part in constructing digital identity, and this means that young people want to be able to express themselves via a set of negotiated rules as to what parts of their constructed identity and information others may be able to see. Through the open-ended interview process, possible solutions emerged. Five uses expressed a desire for 'art gallery' features for content, so visitors could come and browse selected images/sounds/text without being able to copy and re-distribute them.

In order to communicate these findings to the technologists in the Secure Identity Management project, a scenario was developed. It was in keeping with Cooper's (1999) approach in that it employed user archetypes to convey user needs and in keeping with Carroll's (2003) method in that it depicted a scenario of future interaction. The scenario, called the 'Trophy Room' essentially embodies the user needs from the studies by providing a digital art gallery where users can archive and display their multimedia content. It resides on the user's mobile phone, although the Trophy Room can be accessed via the Internet. Selected visitors can then come and browse images/sounds/texts without being able to copy and re-distribution them. This solves the first user 
need that while users are happy to share their content, it is more desirable if they can maintain it in their own space where visitors can come and listen or look.

The Trophy Room provides a place to archive and display images which makes it a logical site for content distribution. This addresses the second user need for better management of multimedia content. User can then 'cut and paste' the desired bits of content into a central token which they can then be SMS/MMS or emailed to selected friends. Furthermore, users would be able to have a choice over what the tokens looked like. For example, the token could be a text message embedded with pictures, or a picture embedded with sound bytes.

Finally, the user studies indicated that the third user need for multimedia content sharing as social communication to be successful is that the content has to be seamlessly distributed across platforms so that experiences can be shared instantaneously. When the scenario was presented to designers during a workshop for the Secure Identity Management project, ways in which content could be carried across platforms included the use of MPEG21 and the use of instant messaging and peer-topeer systems such as Jabber and JXTA.

In order to ensure rigour, the Trophy Room scenario was returned to seven users in the studies. A written description of the Trophy Room scenario was left with the users and they were asked to write any comments they had on the back of paper. The scenarios were picked up a few days later and when possible, a brief discussion in relation to the users' comments took place. This was to be the most interesting part of the research because the scenario produced a high level of user feedback, providing not only a means for the users to reflect further upon their own use, but for them to suggest potential additions to the scenario.

This indicates the effectiveness of scenarios, not only for communicating with computer scientists, but essentially as a form of 'Cultural Probe' (Gaver, et al: 1999). In this case, the use of a scenario proved helpful in filling in the gaps in the user requirements left by the open-ended interviews. The use of both methods combined to provide an in-depth understanding of the participants' use of content production as social communication. This was supported by Wixon who stated that "different qualitative methods tend to complement each other, and other approaches. When the results gathered from different techniques point to similar conclusions, our confidence in the conclusions is increased" (Wixon: 1995). It is important to note that the seven users who were selected to review the scenarios were chosen because of their ability to provide critical feedback.

Crabtree et al point out that "Cultural Probes are not analytic devices but 'reflect' the local culture of participants and are drawn upon to inspire design"(2003). This held true when using the Trophy Room scenario as a form of cultural probe in that giving the scenario back to users helped make the leap from user need to design solution. The users provided valuable insights into how the Trophy Room design could be improved to help the user meet their social and cultural goals. It emerged that users would not just want visitors to the Trophy Room to access all the content that was there, for example, there would be different groups of people with whom they would want to share different photos. Six out of seven users stated that the idea of just providing free access for all would be highly undesirable because photos were often specific to events and only people that were at the events should have access to the photos. Therefore, an important part of the Trophy Room scenario became that 'selected' others would have access to it or parts of it and amongst these selected others different visitors would be granted different levels of access. For example, only a best friend would be allowed to see the picture of the blind date the night before, but a video of a swimming race win could be accessible to any visitor. So in a sense the Trophy Room has a different look depending on who has access to it. For this to be achieved the mobile device must allow peer-to-peer authentication that can be easily controlled. 


\section{POTENTIAL ACCESS LEVELS}

When the Trophy Room scenario was returned again to the users, all seven users agreed that this level of control was an important addition and that part of the pleasure of having content displayed in the Trophy Room was deciding who got to see what. A table was developed to map out how visitors would be provided with different levels of access. This could be done by setting up profiles so that when they try and enter the trophy room the profile group that the owner of the phone set up for the visitor automatically grants them a level of access. The table was then returned to the seven users and their feedback was refined (Table 1). The idea of a 'day pass' was included so someone could see a particular picture from an event once, but then not return unless invited. Furthermore, three users indicated that a desirable feature would be if selected visitors could also contribute their own content, so that if for example, a group of friends went to an event, visitors at that event could add their own photos as well.

\begin{tabular}{|l|l|l|l|l|}
\hline Access Profile & $\begin{array}{l}\text { Areas } \\
\text { Accessed }\end{array}$ & Potential Visitor & Content Allowed & Duration \\
\hline Gold Pass & $\begin{array}{l}\text { Access All } \\
\text { Areas }\end{array}$ & Best friend, partner & $\begin{array}{l}\text { Visitors can view all } \\
\text { content and also } \\
\text { contribute their own } \\
\text { images, text and sounds } \\
\text { etc. }\end{array}$ & Unlimited \\
\hline VIP & $\begin{array}{l}\text { High Level } \\
\text { Access }\end{array}$ & $\begin{array}{l}\text { Friends, close } \\
\text { relatives, trusted } \\
\text { work friends. }\end{array}$ & $\begin{array}{l}\text { Same as a Gold Pass but } \\
\text { a VIP visitor would not } \\
\text { have access to every } \\
\text { single part of the trophy } \\
\text { room. }\end{array}$ & Unlimited \\
\hline $\begin{array}{l}\text { General } \\
\text { Admission }\end{array}$ & $\begin{array}{l}\text { Access to the } \\
\text { 'sanitized' part } \\
\text { of the trophy } \\
\text { room. }\end{array}$ & $\begin{array}{l}\text { Parents, Colleagues } \\
\text { at work }\end{array}$ & $\begin{array}{l}\text { The general admission } \\
\text { lets visitors into a } \\
\text { controlled part of the } \\
\text { trophy room. General } \\
\text { admission visitors can't } \\
\text { post their own content. }\end{array}$ & Unlimited \\
\hline Day Pass & $\begin{array}{l}\text { Same as } \\
\text { General } \\
\text { Admission. }\end{array}$ & $\begin{array}{l}\text { Visitors that may } \\
\text { want to see specific } \\
\text { content. }\end{array}$ & $\begin{array}{l}\text { Same as general } \\
\text { admission. }\end{array}$ & Expires after \\
& & Table hours. \\
\hline
\end{tabular}

Table 1: Potential Access Levels

\section{CONCLUSION}

The studies described here show that $3 \mathrm{G}$ phones offer young people the opportunity to communicate through content that they have produced themselves; however, this practice is restricted by fears that the privacy of home produced content can not be protected, archiving difficulties and finally limitations such as the incompatibility of handsets. Users reported that these fears and limitations force them to resort to channels where they can download, for a fee, commercially produced content. This indicates that the challenge for designers is to facilitate users in the creation, protection and management of their own multimedia content that they can seamlessly distribute across platforms. The Trophy Room scenario encapsulates a response to these user problems in a manner that can be used by designers. It suggests a series of design implications and demonstrates how dynamic 
artefacts created and managed on $3 \mathrm{G}$ phones will afford users with the ability to broadcast their own personal experiences beyond current technology. This means that users can move past the limits of current technologies that have the potential to render them as passive consumers of commercialised ring tones and celebrity pictures.

\section{REFERENCES}

Carroll, John. 2003. HCI Models, Theories, and Frameworks. Calif.: Morgan Kaufmann.

Cooper, Allen. 1999. The Inmates are Running the Asylum. Indianapolis: SAMS.

Counts, Scott, and Fellheimer, Eric. 2004. Supporting Social Presence through Lightweight Photo Sharing on and off the Desktop. In Proceedings of the 2004 Conference on Human Factors in Computing Systems: ACM Press.

Crabtree, A, Hemmings, T, Rodden, T, Cheverst, K, Clarke, K, Dewsbury, G, Hughes, J and Rouncefield, M. 2003. Designing with Care: Adapting Cultural Probes to Inform Design in Sensitive Settings. Proceedings of OZCHI 2003: Brisbane, Australia.

Gaver, Bill, Dunne, Tony and Pacenti, Elena. 1999. Design: Cultural probes. interactions 6 (1) : 21-29 .

Howard, Steve, Carroll, Jennie. Murphy, John and Peck, Jane. 2002. Using 'Endowed Props' in Scenario-Based Design. In Proceedings of the Second Nordic Conference on HumanComputer Interaction: ACM Press.

Minichello, V., Aroni R., Timewell, E., Alexander, L. 1995. In-depth Interviewing: Researching People, 2nd ed. Melbourne: Longman.

Taylor, A.S., and R. Harper. 2002. The Gift of the Gab: a Design Oriented Sociology of Young People's Use of Mobiles. Paper read at Proceedings of Conference on Human Factors and Computing Systems, CHI.

Wixon, Dennis, ed. 1995. Qualitative Research Methods in Design and Development: ACM Press.

Satchell, C, Singh, S and Zic, J C 2004. The authors assign to OZCHI and educational and nonprofit institutions a non-exclusive licence to use this document for personal use and in courses of instruction provided that the article is used in full and this copyright statement is reproduced. The authors also grant a non-exclusive licence to OZCHI to publish this document in full in the Conference Papers and Proceedings. Those documents may be published on the World Wide Web, CD-ROM, in printed form, and on mirror sites on the World Wide Web. Any other usage is prohibited without the express permission of the authors. 